\title{
Qualidade higiênico-sanitária e prevalência de sorovares de Salmonella em linguiças frescais produzidas artesanalmente e inspecionadas, comercializadas no oeste do Paraná, Brasil
}

\author{
Sanitary quality and prevalence of serovars of Salmonella in handmade \\ and inspected fresh pork sausages sold in western Paraná, Brazil
}

\author{
Marinêz de Souza1*, Fabiana Gisele da Silva Pinto², Eliana Almeida Mira de Bona', \\ Alexandre Carvalho de Moura ${ }^{3}$
}

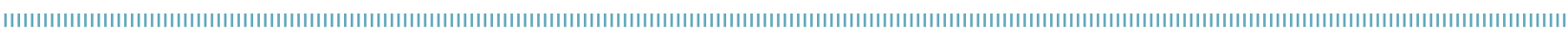

RESUMO: A fabricação de linguiça do tipo frescal requer uma série de etapas de manipulação, o que eleva as possibilidades de contaminação por diversas espécies de micro-organismos patogênicos ou deterioradores. Isso pode comprometer a qualidade microbiológica do produto final e veicular enfermidades a partir de seu consumo. No período de abril a setembro de 2009, foi avaliada a qualidade microbiológica de 40 amostras de linguiça tipo frescal produzidas artesanalmente e inspecionadas pelo Serviço de Inspeção Estadual e Federal nos municípios de Cascavel e Toledo (PR), através da quantificação de coliformes termotolerantes, contagem de Staphylococcus spp., bactérias mesófilas aeróbias estritas e facultativas viáveis, pesquisa de Salmonella spp., Campylobacter spp., Bacillus cereus, Clostridium sulfito-redutores e bolores e leveduras. Os resultados revelaram que $55 \%$ das amostras analisadas de linguiça tipo frescal inspecionadas e artesanais apresentaram-se fora dos parâmetros estabelecidos pela Resoluçáo RDC no 12 , de 2 de janeiro de 2001, da Agência Nacional de Vigilância Sanitária (Anvisa), em pelo menos um dos grupos de micro-organismos estudados. Portanto, pode-se dizer que a linguiça tipo frescal comercializada no oeste do Paraná pode oferecer riscos à saúde da população.

PALAVRAS-CHAVE: linguiça tipo frescal; coliformes termotolerantes; Staphylococcus spp.; Salmonella spp.
ABSTRACT: The manufacture of fresh pork sausage requires a series of manipulation steps, which increases the chances of contamination by several species of micro-organisms, be them pathogenic or deteriorating. This may compromise the microbiological quality of the final product and transmit diseases with consumption. In the period from April to September 2009, the microbiological quality of 40 samples of fresh handmade sausage inspected by the Inspection State and Federal Service in the cities of Cascavel and Toledo (PR) was assessed, through the quantification of thermotolerant coliforms, Staphylococcus spp., viable facultative and strict mesophilic aerobic bacteria, Salmonella spp., Campylobacter spp., Bacillus cereus, Clostridium sulfite reducers, molds and yeasts. The results revealed that $55 \%$ of the analyzed samples of fresh handmade and inspected sausages were not in accordance with the parameters established by Resolution RDC No 12, of January $2^{\text {nd }}, 2001$, from ANVISA, in at least one of the studied groups of micro-organisms. Therefore, we can say the sausages sold in western regions, may present a risk to public health.

KEYWORDS: fresh pork sausage; thermotolerant coliform; Staphylococcus spp.; Salmonella spp. 


\section{INTRODUÇÃO}

Considerando o cenário mundial, constatou-se nas últimas décadas uma acelerada alteração na forma de consumo de carne, com a substituiçáo do produto in natura por outros mais elaborados e de maior praticidade, como é o caso dos embutidos (Sarantópolos, 1992; Lopes et al., 2007).

No Brasil, os embutidos crus ou frescais, elaborados a partir da carne dos suínos, bovinos ou aves, não apresentam padrōes de identidade definidos, verificando-se grande variaçấo na qualidade final do produto, envolvendo aspectos referentes às características sensoriais, à composição centesimal e ao valor nutritivo (Ferrão et al., 1999). Dentre esses produtos cárneos embutidos destaca-se a linguiça do tipo frescal, devido à grande aceitação pelo mercado consumidor, principalmente na regiáo sul do Brasil (Silva et al., 2004; Oliveira et al., 2005).

Dentre os principais pontos críticos da comercialização de embutidos frescais estão as precárias condiçóes físicas e higiênicas das feiras livres, a falta de treinamento dos produtores/proprietários dos estabelecimentos e os produtos fora do prazo de validade (Martins et al., 2006). Como sua fabricação requer uma série de etapas de manipulação, elevam-se as possibilidades de contaminação por diversas espécies de micro-organismos patogênicos ou deterioradores, o que pode comprometer a qualidade microbiológica do produto final (MARQues et al., 2006).

Diante do exposto, o presente trabalho objetivou avaliar a qualidade higiênico-sanitária da linguiça tipo frescal com produção artesanal e com produção inspecionada, através da quantificaçáo de coliformes termotolerantes, contagem de Staphylococcus coagulase positiva, bactérias mesófilas aeróbias estritas e facultativas viáveis, pesquisa de Campylobacter spp., Bacillus cereus, Clostridium sulfito-redutores, bolores e leveduras, assim como a pesquisa e sorotipagem de Salmonella spp. Posteriormente, tais resultados foram comparados aos limites microbiológicos estabelecidos pela legislaçáo nacional.

\section{MATERIAL E MÉTODOS}

Foram analisadas 40 amostras de linguiça tipo frescal, sendo que 20 eram provenientes de produção inspecionada pelo Serviço de Inspeção Estadual e Federal e 20 de produção artesanal, comercializadas em feiras livres, supermercados e padarias nos municípios de Cascavel e Toledo (PR). A coleta foi realizada no período de abril a setembro de 2009, sendo as amostras acondicionadas em caixas isotérmicas e transportadas imediatamente ao laboratório de Microbiologia e Biotecnologia da Universidade Estadual do Oeste do Paraná (UNIOESTE). Elas foram submetidas às análises microbiológicas de coliformes termotolerantes, Staphylococcus coagulase positiva, contagem de bactérias mesófilas aeróbias estritas e facultativas viáveis, pesquisa de Bacillus cereus, Clostridium sulfito-redutores, bolores e leveduras (BrasiL, 2003), Campylobacter spp. (Carvalho, 1992) e Salmonella spp. (Iso 6579, 2002).

Os dados agrupados foram analisados por método não paramétrico. Como não atenderam os pressupostos para realizar o teste do qui-quadrado (amostra > 40; célula com valores > 5), os dados foram analisados quanto à ocorrência pelo Teste Exato de Fisher, com teste de acompanhamento de resíduos ajustados.

\section{RESULTADOS E DISCUSSÃO}

Observaram-se que $100 \%$ das amostras de linguiça tipo frescal produzidas artesanalmente e sob inspeção demonstraram a presença de coliformes termotolerantes (Tabela 1), grupo de micro-organismos utilizado na determinação de condições higiênico-sanitárias na produção de alimentos, segundo Almeida et al. (2002). Sua presença é um indicativo da manipulação incorreta e da falta da aplicação de procedimentos de boas práticas de fabricação, podendo ser considerado um indicativo de contaminação de origem fecal. Isso evidencia risco para a saúde dos consumidores, devido à alta patogenicidade do micro-organismo (SALOTTI et al., 2006). O processo de moagem pelo qual a carne in natura passa favorece a contaminaçấo por micro-organismos, pois aumenta a superfície de contato e proporciona a incorporaçáo de resíduos de moagens anteriores (Almeida et al., 2002).

Resultados semelhantes aos obtidos nesse estudo também foram encontrados por CORTEZ et al. (2004) que, ao analisarem 106 amostras de linguiça tipo frescal de frango, mista e suína fabricadas artesanalmente em Jaboticabal (SP), constataram a presença de coliformes termotolerantes em $73,6 \%$ das amostras, e de E. coli em 38,7\% das linguiças. Marques et al. (2006) avaliaram a qualidade higiênico-sanitária de linguiças frescal coletadas em Três Coraçôes e em Lavras (MG), sendo que de 40 amostras analisadas, $35 \%$ encontraram-se fora do padrão vigente para coliformes termotolerantes. Das 16 amostras de linguiça tipo frescal suínas analisadas por Dias et al. (2008), duas $(12,5 \%)$ apresentaram-se fora dos padróes microbiológicos para coliformes termotolerantes. Já Bezerra et al. (2012), Marçal et al. (2010) e Oliveira et al. (2010) não encontraram valores acima dos parâmetros legais permitidos para as contagens de coliformes termotolerantes nas linguiças frescais comercializadas na Paraíba (PB), Alfenas (MG) e Niterói (RJ), respectivamente.

Além do grupo de micro-organismos citado, a alta incidência de Staphylococcus coagulase positiva em carnes comercializadas em feiras livres também sugere que esses produtos passem por demasiado processo de manipulação. Sendo possivelmente de origem clandestina, sem fiscalização veterinária, não 
Tabela 1. Contagem de coliformes termotolerantes, Staphylococcus coagulase positiva, bactérias mesófilas aeróbias estritas e facultativas viáveis e bolores e leveduras nas amostras de linguiça tipo frescal, produzidas artesanalmente e inspecionadas, comercializadas no oeste do Paraná durante o período de abril a setembro de 2009.

\begin{tabular}{llccccccc}
\multirow{2}{*}{ Faixa de Contagem } & \multicolumn{2}{c}{ NMP/g de CT } & \multicolumn{2}{c}{ UFC/g de SCP } & \multicolumn{2}{c}{ UFC/g de BM } & \multicolumn{2}{c}{ UFC/g de BL } \\
\cline { 2 - 8 } & A (\%) & I (\%) & A (\%) & I (\%) & A (\%) & I(\%) & A (\%) & I (\%) \\
\hline $1,0 \times 10^{1}-5,0 \times 10^{2}$ & $1 \mathrm{~b}(5)$ & $10 \mathrm{a}(50)$ & $5 \mathrm{~b}(25)$ & $15 \mathrm{a}(75)$ & $\mathrm{Ob}(0)$ & $12 \mathrm{a}(60)$ & $\mathrm{Ob}(0)$ & $7 \mathrm{a}(35)$ \\
\hline $5,1 \times 10^{2}-5,0 \times 10^{3}$ & $3 \mathrm{a}(15)$ & $5 \mathrm{a}(25)$ & $11 \mathrm{a}(55)$ & $4 \mathrm{~b}(20)$ & $4 \mathrm{a}(20)$ & $7 \mathrm{a}(35)$ & $1 \mathrm{~b}(5)$ & $7 \mathrm{a}(35)$ \\
\hline $5,1 \times 10^{3}-5,0 \times 10^{4}$ & $3 \mathrm{a}(15)$ & $2 \mathrm{a}(10)$ & $2 \mathrm{a}(10)$ & $1 \mathrm{a}(5 \mathrm{a})$ & $10(50)$ & $1 \mathrm{~b}(5)$ & $1 \mathrm{a}(5)$ & $5 \mathrm{a}(25)$ \\
\hline $5,1 \times 10^{4}-5,0 \times 10^{5}$ & $6 \mathrm{a}(30)$ & $3 \mathrm{a}(15)$ & $2 \mathrm{a}(10)$ & $\mathrm{Oa}(\mathrm{Oa})$ & $3(15)$ & $\mathrm{Oa}(0)$ & $9 \mathrm{a}(45)$ & $1 \mathrm{~b}(5)$ \\
\hline $5,1 \times 10^{5}-5,0 \times 10^{6}$ & $7 \mathrm{a}(35)$ & $\mathrm{Ob}(0)$ & $\mathrm{Oa}(0)$ & $\mathrm{Oa}(\mathrm{Oa})$ & $1(5)$ & $\mathrm{Oa}(0)$ & $8 \mathrm{a}(40)$ & $\mathrm{Ob}(0)$ \\
\hline $5,1 \times 10^{6}-5,0 \times 10^{8}$ & $\mathrm{Oa}(0)$ & $\mathrm{Oa}(0)$ & $\mathrm{Oa}(0)$ & $\mathrm{Oa}(\mathrm{Oa})$ & $2(10)$ & $\mathrm{Oa}(0)$ & $1 \mathrm{a}(5)$ & $\mathrm{Oa}(0)$ \\
\hline
\end{tabular}

Dados originais analisados na linha para cada bactéria, pelo Teste exato de Fisher com teste de acompanhamento de resíduos, com $5 \%$ de significância. A: artesanal; I: inspecionada; CT: coliformes termotolerantes; SCP: Staphylococcus coagulase positiva; BM: bactérias mesófilas aeróbias estritas e facultativas viáveis; BL: bolores e leveduras; NMP/g: número mais provável por grama); UFC: unidades formadoras de colônia por grama.

há como assegurar precisamente as condiçôes higiênico-sanitárias da carne utilizada como matéria-prima e dos produtos derivados (LUNDGREN et al., 2009).

Sendo assim, e considerando os dados encontrados no presente estudo na contagem de Staphylococcus coagulase positiva, verificam-se que esses se assemelham aos encontrados por BARBosa et al. (2003), ao avaliarem 22 amostras de linguiças frescais de carne suína comercializadas no município de Sete Lagoas (MG). Os autores constataram que apenas uma amostra apresentou níveis de contaminação por Staphylococcus coagulase positiva superior à concentraçáo estabelecida pela legislação vigente. MARQues et al. (2006) verificaram que 35\% das amostras de linguiça tipo frescal adquiridas em Lavras e Três Coraçóes encontravam-se impróprias para o consumo, podendo oferecer riscos à saúde do consumidor quanto à presença de Staphylococcus coagulase positiva. Marçal et al. (2010) encontraram apenas duas (14\%) amostras em desacordo com a legislação. Já TeSSMANn et al. (2001), ao analisarem 25 amostras de linguiça tipo frescal de carne suína da cidade de Pelotas (RS), constataram que todas as amostras encontraram-se dentro dos padróes microbiológicos permitidos para esse micro-organismo, resultado que se aproxima do obtido para as amostras inspecionadas neste estudo.

Ainda que a legislação náo contemple as contagens de bactérias mesófilas aeróbias estritas e facultativas viáveis e de bolores e leveduras, devido à importância desses grupos de micro-organismos na indústria alimentícia, realizou-se o isolamento deles nas amostras analisadas (Tabela 1).

Para as bactérias mesófilas aeróbias estritas e facultativas viáveis, as amostras artesanais analisadas tiveram contagens de $5,1 \times 10^{2} \mathrm{UFC} / \mathrm{g}$ a $5,0 \times 10^{8} \mathrm{UFC} / \mathrm{g}$, enquanto as inspecionadas foram de $1,0 \times 10^{1} \mathrm{UFC} / \mathrm{g}$ a $5,0 \times 10^{4} \mathrm{UFC} / \mathrm{g}$. SABIONI et al. (1999) afirmaram que produtos cárneos embutidos geralmente apresentam carga microbiana elevada de micro-organismos mesófilos devido ao intenso manuseio e aos equipamentos e condimentos contaminados. Já segundo LUNDGREN et al. (2009), a presença da contagem de mesófilos sugere que as carnes tanto podem ter sido armazenadas em condiçóes higiênico-sanitárias inadequadas como podem ter sido contaminadas devido às condiçóes de higiene deficitárias dos locais de abate, processamento, exposiçáo e comercialização, bem como dos manipuladores em geral.

Similarmente a este estudo, Ritter et al. (2003), analisando linguiças coloniais no Rio Grande do Sul, encontraram contagens de mesófilos entre $10^{7}$ e $10^{8} \mathrm{UFC} / \mathrm{g}$, indicando que a manipulação dos produtos tenha ocorrido sob condiçôes deficientes de higiene. LourENÇÃo et al. (2005) ressaltaram ainda a importância que os condimentos também podem assumir na contaminação final quando utilizados em produtos do tipo frescal. Nas amostras de pimenta-do-reino e orégano analisadas por esses autores, $36,4 \%$ e $6,1 \%$, respectivamente, estavam em desacordo com a legislação nacional vigente.

A contagem de bolores e leveduras variou entre 5,1 $\mathrm{x}$ $10^{2} \mathrm{UFC} / \mathrm{g}$ e 5,0 x $10^{8} \mathrm{UFC/g}$, sendo que os maiores valores observados para as amostras de linguiça artesanais foram de 5,1 x $10^{6} \mathrm{UFC/g}$ a 5,0 x $10^{8} \mathrm{UFC/g}$, e das inspecionadas, de $5,1 \times 10^{4} \mathrm{UFC} / \mathrm{g}$ a $5,0 \times 10^{5} \mathrm{UFC} / \mathrm{g}$, correspondendo a $\%$ em ambas as amostras (Tabela 1). A presença de bolores e leveduras em índices elevados nos alimentos fornece informaçôes sobre condiçôes higiênicas deficientes nos equipamentos e utensílios, matéria-prima contaminada, falha no processamento ou na estocagem (VELD, 1996). Os resultados obtidos no presente estudo corroboram os valores encontrados por MARÇAL et al. (2010) em linguiças frescais, nos quais as contagens variaram de ausentes a 4,4 x 10 UFC/g, e por LuNDGRen et al. (2009), com valores médios de $2,7 \times 10^{5} \mathrm{UFC} / \mathrm{g}$ em carnes comercializadas em feiras livres.

Com base na estatística não paramétrica aplicada aos dados, confirmou-se a maior ocorrência de micro-organismos nas faixas de contagem em amostras de linguiças não inspecionadas quando comparadas às inspecionadas.

Para as pesquisas de Campylobacter spp., Bacillus cereus e Clostridium sulfito-redutores nas amostras, nenhuma apresentou resultado positivo, portanto, este resultado foi satisfatório por se tratarem de micro-organismos patogênicos que representam risco à saúde do consumidor (BRASIL, 2001).

A bactéria Campylobacterspp. apresenta sensibilidade a concentraçôes de cloreto de sódio superiores a 1,5\% (WiLliams et al., 1994). 
Como a linguiça tipo frescal possui outros condimentos além de sal, o isolamento desse micro-organismo nas amostras analisadas pode ter sido influenciado (Cortez et al., 2004). Além disso, pode ainda ter ocorrido a competiçấo com a microbiota autóctone (Franco, 1995), ou a sobrevivência de Campylobacter spp. pode tornar-se reduzida pela presença de outros micro-organismos devido à redução do valor do $\mathrm{pH}$ e à produção de ácidos orgânicos (VARnam; Evans, 1991).

A ausência de contagem de Bacillus cereus encontrada no presente estudo também foi obtida por MARÇAL et al. (2010), ao analisarem amostras de linguiça tipo frescal no município de Alfenas (MG). A presença de Bacillus cereus em alimentos está, na maioria das vezes, relacionada à manipulação exacerbada associada ao armazenamento e ao acondicionamento em temperatura inadequada, sendo que o consumo de alimentos que contenham uma concentraçáo superior a $10^{6} \mathrm{~B}$. cereus $/ \mathrm{g}$ pode resultar em intoxicaçáo alimentar (Gomes et al., 2004).

No grupo dos Clostridium sulfito-redutores, Clostridium perfringens é o principal representante. A temperatura de refrigeração na qual o produto é armazenado, aliada à competição exercida pela microbiota psicrotrófica acompanhante, pode dificultar o crescimento do micro-organismo (Forsythe, 2002). Semelhantemente aos resultados encontrados nesta pesquisa, Garcia (2000), Silva et al. (2002) e Marçal et al. (2010) também não detectaram a presença desse grupo de micro-organismos nas amostras pesquisadas (Londrina (PR), Lavras (MG), Pelotas (RS) e Alfenas (MG), respectivamente). No entanto, BromberG et al. (2001), trabalhando com 376 amostras de linguiça tipo frescal no município de Campinas (SP), encontraram esse grupo bacteriano em $0,6 \%$ das amostras.

Em relaçáo à análise de Salmonella spp., nas amostras de linguiça tipo frescal analisadas neste trabalho, somente houve prevalência nas artesanais, sendo identificados os sorotipos: Salmonella enterica subs. enterica, Salmonella Derby, Salmonella Agona, Salmonella Enteritidis e Salmonella Typhimurium. Assim como os resultados desse estudo, outros autores também têm isolado esse micro-organismo em embutidos e produtos similares.
Castagna et al. (2004) analisaram 99 porçóes de massa destinadas à fabricação de embutidos tipo frescal coletadas em um frigorífico sob inspeção federal, localizado no Rio Grande do Sul, e isolaram Salmonella spp. de 90 (93,9\%) porçôes, sendo encontrados os sorotipos Salmonella Bredeney, SaintPaul, Panamá e Typhimurium. Cortez et al. (2004) analisaram 106 amostras de linguiça do tipo frescal, de produçáo artesanal e inspecionadas, e isolaram Salmonella spp. em nove $(8,5 \%)$ amostras, estando presentes os sorotipos Salmonella enterica subs. enterica, Salmonella Derby, Salmonella Agona, Salmonella Rissen e Salmonella spp. Spricigo et al. (2008) encontraram prevalência de Salmonella spp. em 12,8\% das 125 amostras de linguiça tipo frescal analisadas, sendo o sorotipo Typhimurium o mais encontrado.

Apesar de todos os sorotipos de Salmonella spp. serem considerados potencialmente patogênicos para humanos, a maioria dos surtos tem sido relacionada aos sorotipos Enteritidis e Typhimurium. No Brasil, os sorotipos Typhimurium, Agona, Infantis e Enteritidis foram identificados em casos de infecção alimentar em humanos, sendo que o sorotipo Enteritidis tem sido o mais encontrado (TAunay et al., 1996; Esper et al., 1998; Jakabi et al., 1999), semelhantemente ao observado no presente estudo.

Levando-se em consideração os parâmetros microbiológicos estudados e a legislação nacional vigente, calculou-se o percentual das amostras de linguiças tipo frescal que se apresentaram de acordo ou em desacordo com cada grupo de micro-organismos (Tabela 2).

Verificou-se que do total de 40 amostras analisadas, 17 (85\%) e 5 (27\%) amostras artesanais e inspecionadas, respectivamente, apresentaram-se em desacordo com os limites máximos estabelecidos pela legislação vigente para pelo menos um dos parâmetros analisados. Sendo assim, do total de amostras, somente $3(15 \%)$ artesanais apresentaram-se de acordo, somando-se 22 (55\%), dentre artesanais e inspecionadas, em desacordo com os padróes quanto ao perfil microbiológico de contaminação.

A partir dos dados obtidos e analisados, pode-se dizer que os resultados deste trabalho foram semelhantes aos encontrados por outros autores, em outras regiôes do país, indicando

Tabela 2. Percentual de amostras artesanais e inspecionadas de linguiças tipo frescal comercializadas no oeste do Paraná, de acordo ou desacordo com os padrões microbiológicos estabelecidos pela legislação nacional vigente para cada grupo de micro-organismos estudado.

\begin{tabular}{|c|c|c|c|c|c|}
\hline \multirow{2}{*}{ Micro-organismo } & \multirow{2}{*}{ Limite* } & \multicolumn{2}{|c|}{ Artesanais } & \multicolumn{2}{|c|}{ Inspecionadas } \\
\hline & & Acordo (\%) & Desacordo (\%) & Acordo (\%) & Desacordo (\%) \\
\hline C. Termotolerantes (NMP/g) & $\leq 5,0 \times 10^{3}$ & 20 & 80 & 75 & 25 \\
\hline S. coagulase positiva (UFC/g) & $\leq 5,0 \times 10^{3}$ & 80 & 20 & 95 & 5 \\
\hline Bactérias mesófilas (UFC/g) & - & - & - & - & - \\
\hline Campylobacter spp./25g & Ausência & 100 & 0 & 100 & 0 \\
\hline Bacillus cereus / $25 \mathrm{~g}$ & - & - & - & - & - \\
\hline C. sulfito redutores (UFC/g) & $3,0 \times 10^{3}$ & 100 & 0 & 100 & 0 \\
\hline Bolores e leveduras (UFC/g) & - & - & - & - & - \\
\hline Salmonella spp. & Ausência & 70 & 30 & 100 & 0 \\
\hline
\end{tabular}

*Brasil (2001). NMP/g: número mais provável por grama; UFC/g: unidades formadoras de colônia por grama. 
que a linguica tipo frescal, principalmente a de produção artesanal, é um problema sanitário que carece de mais atenção em nível nacional. Também é importante ressaltar que toda a matéria-prima usada para a elaboração de linguiça deve ser submetida aos processos de inspeção prescritos no Regulamento de Inspeção Industrial e Sanitária de Produtos de Origem Animal (RIISPOA), além do produto final, de acordo com o Decreto no 30.691, de 29/03/1952, do Ministério da Agricultura, Pecuária e Abastecimento (BRASIL, 1981), visando assim minimizar os riscos de saúde ao consumidor.

\section{CONCLUSÕES}

Os resultados obtidos neste estudo indicam que 55\% das amostras analisadas de linguiça tipo frescal, inspecionadas e artesanais, apresentaram-se fora dos parâmetros estabelecidos pela Resolução RDC No 12 da ANVISA (BrasiL, 2001) em pelo menos um dos grupos de micro-organismos estudados. Sendo assim, pode-se dizer que a linguiça tipo frescal comercializada no oeste do Paraná pode oferecer riscos à saúde da população.

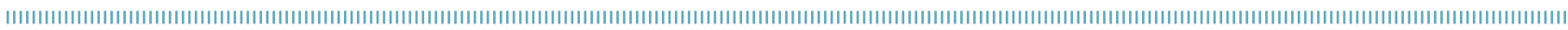

\section{REFERÊNCIAS}

ALMEIDA, A.S.; GONÇALVES, P.M.R.; FRANCO, R.M. Salmonella em corte de carne bovina inteiro e moído. Higiene Alimentar, São Paulo, v.16, n.96, p.77-81, 2002.

BARBOSA, M.B.C.; THIAGO, M.S.; SANTOS, W.L.M.; MARTINS, N.E. Avaliação da qualidade microbiológica de linguiças frescais de carne suína no município de Sete Lagoas. Higiene Alimentar, São Paulo, v.17, n. 104/105, p.20-21, 2003.

BEZERRA, M.V.P.; ABRANTES, M.R.; SILVESTRE, M.K.S.; SOUSA, E.S.; ROCHA, M.O.C.; FAUSTINO, J.G.; SILVA, J.B.A. Avaliação microbiológica e físico-química de linguiça toscana no Município de Mossoró, RN. Arquivos do Instituto Biológico, São Paulo, v.79, n.2, p.297-300, 2012.

ANVISA - AGÊNCIA NACIONAL DE VIGILÂNCIA SANITÁRIA. Resolução RDC no 12, de 2 de janeiro de 2001. Regulamento Técnico sobre padrões microbiológicos para alimentos. Diário Oficial da União. Brasília, 2 de janeiro de 2001.

MINISTÉRIO DA AGRICULTURA, PECUÁRIA E ABASTECIMENTO. Instrução Normativa $\mathrm{n}^{\circ} 62$, de 26 de agosto de 2003. Métodos Analíticos para Análises Microbiológicas para Controle de Produtos de Origem Animal e Água. Diário Oficial da União. Brasília, 18 de setembro de 2003.

MINISTÉRIO DA AGRICULTURA, PECUÁRIA E ABASTECIMENTO. Regulamento da Inspeção Industrial e Sanitária de Produtos de Origem Animal-RIISPOA: (aprovado Decreto n.30.691, de 29/03/1952; alterado pelo Decreto n. 1.255 de 25/06/1962). Diário Oficial da União. Brasília, 1981. 40p.

BROMBERG, R.; YAMADA, E.A.; MIYAGUSKU, L. Estudos da qualidade microbiológica de carnes e produtos cárneos crus resfriados. In: CONGRESSO BRASILEIRO DE CIÊNCIA E TECNOLOGIA DE ALIMENTOS, 17, 2001, Fortaleza, CE. Anais. Fortaleza: 2001 . p. 122.

CARVALHO, A.C.F.B. Isolamento e identificação de Campylobacter spp. em fezes diarréicas de suínos na região de Ribeirão Preto, SP. Aspectos da Patogenicidade. 1992. 72f. Tese (Doutorado em Microbiologia). Universidade de São Paulo, São Paulo, 1992.
CASTAGNA, S.M.F.; SCHWARZ, P.; CANAL, C.W.; CARDOSO, M.R.I. Prevalência de suínos portadores de Salmonella sp. ao abate e contaminação de embutidos tipo frescal. Acta Scientiae Veterinariae, Porto Alegre, v.32, n.2, p.141-147, 2004.

CORTEZ, L.L.; CARVALHO, A.C.F.B.; AMARAL, L.A.; SALOTTI, B.M.; VIDAL-MARTINS, A.M.C. Coliformes fecais, estafilococos coagulase positiva (ECP), Salmonella spp. e Campylobacter spp. em linguiça frescal. Alimentos e Nutrição, Araraquara, v. 15, n.3, p.215-220, 2004.

DIAS, P.A.; DA CONCEIÇÃO, R.C.S.; COELHO, F.J.O.; TEJADA, T.S.; SEGATTO, M.; TIMM, C.D. Qualidade higiênico-sanitária de carne bovina moída e de embutidos frescais comercializados no sul do Rio Grande do Sul, Brasil. Arquivos do Instituto Biológico, São Paulo, v.75, n.3, p.359-363, 2008.

ESPER, M.R.N.R.; FREITAS, A.M.; FERNANDES, S.A. Salmonella: Sorotipos identificados das cepas isoladas de pacientes hospitalizados e não hospitalizados, na região de Presidente Prudente, SP, no período de 1978-1997. Instituto Adolfo Lutz, São Paulo, v.57, p.45-50, 1998.

FERRÃO, S.P.B.; SANTOS, W.L.M.; VERSIANI, C.V. Determinação de nitritos em linguiças frescais comercializadas em Belo Horizonte M.G. Higiene Alimentar, São Paulo, v. 13, n.61, 1999.

FORSYTHE, S.J. Microbiologia da segurança alimentar. São Paulo: Artmed, 2002. 424p.

FRANCO, R.M. Diferentes métodos de isolamento de Campylobacter jejuni em alimentos. Brasileira de Ciências Veterinárias, Rio de Janeiro, v.2, n.3, p.91-96, 1995.

GARCIA, S. Avaliação da segurança microbiológica de linguiças tipo frescal coletadas no município de Londrina. In: Congresso BRASILEIRO DE CIÊNCIA E TECNOLOGIA DE ALIMENTOS, 1, 2000, Fortaleza. Anais. Fortaleza: 2000. p. 112.

GOMES, L.P.; RODRIGUES, M.M.; SOARES, G.; BARONI, F.A.; SOUZA, M.M.S. Bacillus cereus em amostras de doces industrializados comercializados por ambulantes nos municípios de Seropédica e Itaguaí - RJ. Universidade Rural: Série Ciências da Vida, Seropédica, RJ: EDUR, v.24, n.2, p.181-184, 2004. 
ISO 6579. INTERNATIONAL ORGANIZATION FOR STANDARDIZATION. Microbiology of food and animal feeding stuffs - Horizontal method for the detection of Salmonella spp., $4^{\mathrm{a}}$ ed., 2002.

JAKABI, M.; BUZZO, A.A.; RISTORI, C.A. Observações laboratoriais sobre surtos alimentares de Salmonella sp., ocorridos na grande São Paulo, no período de 1994 a 1997. Revista Instituto Adolfo Lutz, São Paulo, v.58, n.1, p.47-51, 1999.

LOPES, M.M.; SILVA, L.P.; JUNIOR, C.A.C.; TEODOROS, A.J. ; MANO, S.B.; FREITAS, M.Q.; FRANCO, R.M.; PARDI, H.S. Aspectos bacteriológicos e físico-químicos da linguiça frescal de frango elaborada com diferentes concentrações de polifosfato de sódio. Revista Portuguesa de Ciências Veterinárias, Lisboa, v.102, n.563564, p. $331-338,2007$.

LOURENÇÃO, A.L.; SIQUEIRA, W.J.; MELO, A.M.T.; PALAZZO, S.R.L.; MELO, P.C.T.; COLARICCIO, A. Resistência de cultivares e linhagens de tomateiros a Tomato chlorotic spot virus e a Potato virus Y. Fitopatologia Brasileira, Brasília, v.30, p.609-614, 2005.

LUNDGREN, P.U.; SILVA, J.A.; MACIEL, J.F.; FERNANDES, T.M. Profile of the hygienic-sanitary quality of bovine meat marketed at free markets and public markets of João Pessoa/PB-Brasil. Alimentos e Nutrição, Araraquara, v.20, n. 1, p.1 13-119, 2009.

MARÇAL, K.C.; REIS, N.M.M.O.; CALDARA, F.R.; RIBEIRO, G.E.; OLIVEIRA, N.M.S.; FIOTINI, J.E. Qualidade microbiológica de linguiças frescais artesanais, comercializadas no município de Alfenas, MG. Higiene Alimentar, São Paulo, v.24, n.184/185, p.138-142, 2010.

MARQUES, S.C.; BOARI, C.A.; BRCKO, C.C.; NASCIMENTO, A.R.; PICCOL, R.H. Avaliação higiênico-sanitária de linguiças tipo frescal comercializadas nos municípios de Três Corações e Lavras-MG. Ciência Agrotécnica, Lavras, v.30, n.6, p.1120-1123, 2006.

MARTINS, T.D.D.; BEZERRA, W.I.; BATISTA, E.S.; ARRUDA, J.C.B.; MOREIRA, R.T.; SILVA, L.P.G.; PEREIRA, W.E.; SANTOS, J.G. Avaliação das condições higiênico-sanitárias em estabelecimentos que comercializam embutidos derivados dos suínos em Solânea, PB. In: CONGRESSO LATINO AMERICANO DE SUINOCULTURA, 3, 2006, Foz do Iguaçu, PR. Anais. Foz do Iguaçu: 2006.

OLIVEIRA, M.J.; ARAÚJO, W.M.C.; BORGO, L.A. Quantificação de nitrato e nitrito em linguiças do tipo frescal. Ciência e Tecnologia de Alimentos, Campinas, v.25, n.4, p.736-742, 2005.

OLIVEIRA, M.G.; GRANDA, T.K.V.; LIMA, A.S.; LAER, A.E.V.; CARDOSO, K.R.P.; SILVA, W.P. Qualidade higiênico-sanitária de linguiças tipo frescal produzidas na região sul do Rio Grande do Sul. In: XVIII CONGRESSO DE INICIAÇÃO CIENTÍFICA E XI ENCONTRO DE PÓS GRADUAÇÃO, 18, 2010, Pelotas. Anais. Pelotas: 2010.
RITTER, R.; SANTOS, D.; AGOSTINI, F.S.; CARBONI, A.N.; BERGMANN, G.P. Microbiologia contaminante e patogênica de linguiça (salame) colonial, analisadas em quatro períodos distintos. Higiene Alimentar, São Paulo, v.17, n.113, p.60-66, 2003.

SABIONI, J.G.; MAIA, A.R.P.; LEAL, J.P. Avaliação microbiológica de linguiça frescal comercializada em Ouro Preto - MG. Higiene Alimentar, v.13, n.61, p.110-113, 1999.

SALOTTI, B.M.; CARVALHO, A.C.F.B.; AMARAL, L.A.; VIDAL MARTINS, A.M.C.; CORTEZ, A.L. Qualidade microbiológica do queijo Minas frescal comercializado no município de Jaboticabal, SP, Brasil. Arquivos do Instituto de Biológico, São Paulo, v.73, n.2, p.171-175, 2006.

SARANTÓPOLOS, C.I.G.L. Novas tendências em embalagens de frango. In: CONFERENCIA APINCO DE CIÊNCIA E TECNOLOGIAS AVÍCOLAS. 1, 1992, Santos. Anais. Santos: 1992. p.67-77.

SILVA, W.P.; GANDRA, E.A.; DUVAL, E.H.; JANTZEN, M.M.; TESSMANN, C. LIMA, A.S. Qualidade microbiológica de linguiças mistas do tipo frescal produzidas na cidade de Pelotas (RS). Boletim do Centro de Pesquisa e Processamento de Alimentos, Curitiba, v.20, n.2, 2002.

SILVA, W.P.; LIMA, A.S.; GANDRA, E.A.; ARAUJO, M.R.; MACEDO, M.R.P.; DUVAL, E.H. Listeria spp. no processamento de lingüiça frescal em frigoríficos de Pelotas, RS, Brasil. Ciência Rural, Santa Maria, v.34, n.3, 2004.

SPRICIGO, D.A.; MATSUMOTO, S.R.; ESPÍNDOLA, M.L.; VAZ, E.K.; FERRAZ. S.M. Prevalência e perfil de resistência a antimicrobianos de sorovares de Salmonella isolados de linguiças suínas tipo frescal em Lages, SC. Arquivo Brasileiro de Medicina Veterinária e Zootecnia, Belo Horizonte, v.60, n.2, p.517-520, 2008.

TAUNAY, A.E.; FERNANDES, A.S.; TAVECHIO, A.T. The role of public health laboratory in the problem of Salmonellosis in São Paulo, Brazil. Instituto de Medicina Tropical de São Paulo, São Paulo, v.38, n.2, p.119-127, 1996.

TESSSMANN, C.; LIMA, A.S.; DUVAL, E.H.; MACEDO, M.R.P.; SILVA, W.P. Prevalência de Salmonella sp. e Staphylococcus aureus em linguiças do tipo frescal derivadas de carne suína. In: CONGRESSO BRASILEIRO DE MICROBIOLOGIA, 21, 2001. Foz do Iguaçu. Anais. Foz do Iguaçu: 2001. p.390.

VARNAM, A.H.; EVANS M.G. Foodborne pathogens: an illustrated text. St Louis: Moby-Year Book, 1991. p.209-34.

VELD, J.H.J.H. Microbial and biochemical spoilage of foods: an overview. International Journal of Food Microbiology, Oxford, v.33, p.1-18, 1996.

WILLIAMS, S.T.; SHARPE, M.E.; HOLT, J.G. Bergery's manual of determinative bacteriology. Baltimore: Williams \& Wilkins, 1994. 787p. 